\title{
Efeitos de dietas com níveis crescentes de milho no metabolismo ruminal de energia e proteína em bubalinos ${ }^{1}$
}

\author{
Teresa Cristina Alves ${ }^{2}$, Raul Franzolin ${ }^{3}$, Paulo Henrique Mazza Rodrigues ${ }^{4}$, Ana Carolina \\ Alves $^{2}$
}

\footnotetext{
${ }^{1}$ Apoio financeiro com bolsa de mestrado pela CAPES.

2 Programa de Pós-Graduação em Qualidade e Produtividade Animal da FZEA-USP.

${ }^{3}$ Departamento de Zootecnia, Faculdade de Zootecnia e Engenharia de Alimentos, Universidade de Sao Paulo, Campus de Pirassununga.

${ }^{4}$ Departamento de Nutrição e Produção Animal, Faculdade de Medicina Veterinária e Zootecnia, Universidade de Sao Paulo, Campus de Pirassununga.
}

RESUMO - Avaliaram-se os efeitos de dietas com níveis crescentes de milho em grão moído (0, 22, 37 e $49 \%$ na MS) em substituição ao feno de coast-cross mantendo-se diferentes relações proteína:carboidratos não-fibrosos $(\mathrm{PB}: \mathrm{CNF}=1,01$; 0,39; 0,33 e 0,27$)$ sobre o metabolismo ruminal de búfalos. Utilizaram-se quatro búfalos fistulados no rúmen, mantidos em delineamento quadrado latino $4 \times 4$, para a coleta de amostras do líquido ruminal, colhidas em cada período experimental (de 28 dias) nos tempos 0, 2, 4 e 8 horas após a alimentação. Em geral, os bubalinos apresentaram boa capacidade tamponante no rúmen, com pH médio alto $(6,70)$ e aumento da ingestão de milho em grão moído. $\mathrm{O}$ acréscimo nos níveis de milho na dieta promoveu aumento da produção de ácido butírico. Somente a dieta com $49 \%$ de milho promoveu melhor fermentação ruminal, com menor propoção de ácidos acético:propiônico. A relação PB:CNF de 1,01 indica deficiência de energia da dieta disponível para microrganismos no rúmen ao longo do dia, enquanto dietas com PB:CNF entre 0,39 e 0,27 promovem fermentações ruminais semelhantes, o que indica sincronismo na utilização de nitrogênio e energia pelos microrganismos no rúmen nessas condições.

Palavras-chave: ácidos graxos voláteis, amônia, búfalo, carboidrato, $\mathrm{pH}$ rúmen, rúmen

\section{Effects of diets with increasing corn levels on the ruminal energy and protein metabolism in buffalo}

\begin{abstract}
The effects of diets with increasing ground corn grain levels $(0,22,37$ and $49 \%$ in the dry matter) substituting coast-cross hay, with different protein:non-fibrous carbohydrate ratios $(\mathrm{CP}: \mathrm{NFC}=1.01 ; 0.39 ; 0.33$ and 0.27 ) were assessed on buffalo ruminal metabolism. Four rumen fistulated buffaloes were used kept in a $4 \times 4$ latin square design, to collect liquid ruminal samples, collected in each experimental period (28 days) at $0,2,4$ and 8 hours after feeding. In general, the buffalo presented good buffering capacity in the rumen, with high mean $\mathrm{pH}(6.70)$ and increase in ground corn intake. The increase in the corn levels in the diet resulted in increased butyric acid production. Only the diet with $49 \%$ corn showed better ruminal fermentation, with a small proportion of acetic:propionic acids. The CP:NFC ratio of 1.01 indicated energy deficiency in the diet available for microorganisms in the rumen throughout the day, although the diets with CP:NFC between 0.39 and 0.27 resulted in similar ruminal fermentations, that indicated synchronization in nitrogen and energy use by the rumen microorganisms under these conditions.
\end{abstract}

Key Words: ammonia, buffalo, carbohydrate, rumen, rumen $\mathrm{pH}$, volatile fatty acids

\section{Introdução}

As funções metabólicas que envolvem o sistema digestivo dos bubalinos ainda não estão bem definidas como em outros ruminantes. A digestão de alimentos é um processo complexo, que envolve microrganismos, enzimas e ações dinâmicas. A proteína da dieta é catabolizada por bactérias e protozoários no rúmen em aminoácidos e amônia que são utilizados para síntese de proteína microbiana, enquanto os carboidratos são fermentados em ácidos graxos voláteis ( $\mathrm{AGV}$ ), que são usados na produção de energia. A eficiência de crescimento microbiano depende da quantidade e da forma de energia disponível no rúmen. 
A boa qualidade da fonte de carboidratos nãoestruturais (CNF) aumenta a produção de $\mathrm{AGV}$ e reduz a concentração de amônia no rúmen, aumentando a eficiência da energia e da produção de carne e leite de bubalinos.

Segundo Cameron et al. (1991), a síntese de proteína microbiana e o crescimento microbiano dependem de adequada quantidade de energia e nitrogênio para a síntese e assimilação de aminoácidos. Um sincronismo entre a degradação ruminal da proteína e dos carboidratos da dieta é necessário para ótimo crescimento microbiano e síntese proteica (Russel \& Hespel, 1981).

A eficiência da produção animal é geralmente limitada pela utilização de energia, e não pelo fornecimento de proteína, embora esse último possa alterar o consumo de alimento alterando a eficiência de produção. Os ácidos graxos voláteis no rúmen fornecem a maior parte da energia absorvida pelos ruminantes, estimada em $50-70 \%$ da energia digestível total. A determinação quantitativa dos processos de fermentação ruminal requer, portanto, medidas precisas de taxa de produção dos AGV.

A relação entre proteína e $\mathrm{CNF}$ representa a situação da disponibilidade de nitrogênio e energia para utilização pelos microrganismos no rúmen para crescimento e multiplicação celular, refletindo sobre a eficiência do processo de fermentação e síntese microbiana no rúmen. $\mathrm{O}$ estudo das melhores combinações entre fontes de proteínas e de carboidratos é de grande relevância em nutrição de ruminantes, especialmente em bubalinos, em decorrência da escassez de informações disponíveis na literatura científica.

Objetivou-se com este trabalho avaliar os efeitos da substituição crescente do feno de gramínea por milho em grão moído, representando diferentes relações proteína:carboidratos não-fibrosos, em dietas para búfalos sobre o metabolismo ruminal, o $\mathrm{pH}$, a produção dos principais AGV e amônia.

\section{Material e Métodos}

O experimento foi realizado no período de $6 / 4 / 2006$ a 27/7/2006 na Faculdade de Zootecnia e Engenharia de Alimentos da Universidade de São Paulo, campus de Pirassununga, utilizando-se quatro búfalos, machos castrados, da raça Mediterrâneo. Os animais foram fistulados e submetidos a implante de cânulas de látex flexível (4' de diâmetro) por técnica cirúrgica adequada. No início do experimento, os búfalos apresentavam-se em média com 14 meses de idade e $328 \mathrm{~kg}$ de peso vivo e foram mantidos individualmente em galpão experimental contendo bebedouro automático e comedouro. $\mathrm{O}$ delineamento utilizado foi o quadrado latino $(4 \times 4)$ com quatro subperíodos de 28 dias, incluindo 21 dias iniciais de adaptação às dietas.

Avaliaram-se dietas à base de feno de coast cross (Cynodon dactylon (L.) Pers), formuladas com quatro níveis de milho em grão moído $(0,22,37$ e 49\% MS) e diversas relações proteína bruta:carboidratos não-fibrosos $(1,01 ; 0,39 ; 0,33$ e 0,26$)$, calculadas a partir da ingestão de matéria seca (Tabela 1).

A quantidade de alimento consumida pelos animais foi controlada diariamente, o que possibilitou determinar quantidade de sobra de até $10 \%$ do fornecido. A dieta foi fornecida duas vezes por dia, distribuída igualmente no período da manhã (às $8 \mathrm{~h}$ ) e da tarde (às $16 \mathrm{~h}$ ). Os búfalos apresentaram padrão de consumo com ampla variação ao longo do dia e individualidade diferenciada, mas com boa aceitabilidade do milho em grão moído no momento do fornecimento. Mistura de sal mineral comercial foi fornecida aos animais antes da alimentação matutina.

Análises bromatológicas foram realizadas no Laboratório de Bromatologia da FZEA/USP, conforme técnica descrita por Silva \& Queiroz (2002). Os carboidratos não-estruturais foram calculados pela seguinte fórmula: $\mathrm{CNF}=100-(\% \mathrm{~PB}+\% \mathrm{EE}+\% \mathrm{MM}+\% \mathrm{FDN})$. Os nutrientes digestíveis totais (NDT) do feno foram estimados a partir do teor de FDN, pela equação NDT $=91,0246-0,57158$ $\%$ FDN (Cappelle, 2001) e os do milho foram estimados em $85 \%$ (NRC, 1989). Houve variação na composição bromatológica do feno de capim coast-cross utilizado durante o experimento. Os valores médios da composição bromatológica do feno e do milho foram: 91,81 e $86,2 \%$ de MS; 8,53 e $11,93 \%$ de PB; 78,04\% e 9,0\% de FDN; 85, 19 e $81,74 \%$ de carboidratos totais; 7,15 e $72,74 \%$ de carboidratos não-fibrosos (CNF); 1,13 e 4,79\% extrato etéreo (EE); 5,15 e 1,53\% de matéria mineral; e 46,42 e $85,00 \%$ de nutrientes digestíveis totais (NDT).

Para determinação de ácidos graxos voláteis, foram colhidas amostras de líquido ruminal durante cada período de coleta nos tempos $0,2,4$ e 8 horas após o fornecimento da primeira alimentação, diretamente do rúmen, via fístula, com uso de bomba de vácuo adaptada para esse fim. As amostras foram acidificadas com ácido metafosfórico $25 \%$ e congeladas a $-10^{\circ} \mathrm{C}$ para posterior análise laboratorial (Erwin et al., 1961). As amostras foram descongeladas em temperatura ambiente, centrifugadas por 10 minutos a $4000 \mathrm{rpm}$ e em seguida passadas em filtro Millipore de $0.22 \mu \mathrm{m}$. As determinações dos ácidos acético, propiônico e butírico nas amostras de líquido ruminal foram realizadas por cromatografia líquida de alta precisão (HPLC) em 
Tabela 1 - Ingestão de matéria seca e nutrientes em búfalos mantidos com dietas com níveis crescentes de milho em grão moído

\begin{tabular}{|c|c|c|c|c|}
\hline \multirow[b]{2}{*}{ Fração ingerida } & \multicolumn{4}{|c|}{ Nível de grão de milho moído (\% MS) } \\
\hline & $0 \%$ & $22 \%$ & $37 \%$ & $49 \%$ \\
\hline Matéria seca do feno (kg) & 4,88 & 4,41 & 3,77 & 3,13 \\
\hline Matéria seca total $(\mathrm{kg})$ & $4,88 \mathrm{~b}$ & $5,65 \mathrm{ab}$ & $5,98 \mathrm{ab}$ & $6,13 \mathrm{a}$ \\
\hline Milho moído (\%) & 0 & 22 & 37 & 49 \\
\hline Matéria seca $\left(\mathrm{g} / \mathrm{kg}^{0,75}\right)$ & $57,37 \mathrm{~b}$ & $67,28 \mathrm{ab}$ & $71,98 \mathrm{a}$ & $73,53 \mathrm{a}$ \\
\hline Fibra em detergente neutro do milho $(\mathrm{kg})$ & $0,0 \mathrm{~d}$ & $0,112 \mathrm{c}$ & $0,202 b$ & $0,27 \mathrm{a}$ \\
\hline Fibra em detergente neutro $(\mathrm{kg})$ & $3,79 \mathrm{a}$ & $3,56 \mathrm{ab}$ & $3,11 \mathrm{bc}$ & $2,69 \mathrm{c}$ \\
\hline Fibra em detergente neutro (\%) & $78,04 \mathrm{a}$ & $62,83 b$ & $52,40 \mathrm{c}$ & $44,25 \mathrm{~d}$ \\
\hline Proteína bruta do feno $(\mathrm{kg})$ & 0,338 & 0,318 & 0,337 & 0,280 \\
\hline Proteína bruta do milho $(\mathrm{kg})$ & $0,0 \mathrm{~d}$ & $0,148 \mathrm{c}$ & $0,268 b$ & $0,362 \mathrm{a}$ \\
\hline Proteína bruta $(\mathrm{kg})$ & $0,338 \mathrm{c}$ & $0,466 b$ & $0,605 \mathrm{a}$ & $0,643 \mathrm{a}$ \\
\hline Proteína bruta:carboidratos não-fibrosos & $1,01 \mathrm{a}$ & $0,39 b$ & $0,33 \mathrm{~b}$ & $0,27 \mathrm{~b}$ \\
\hline Nutrientes digestíveis totais do feno $(\mathrm{kg})$ & $2,26 \mathrm{a}$ & $2,04 \mathrm{ab}$ & $1,74 \mathrm{bc}$ & $1,44 \mathrm{c}$ \\
\hline Nutrientes digestíveis totais do milho $(\mathrm{kg})$ & $0,0 \mathrm{~d}$ & $1,05 \mathrm{c}$ & $1,91 b$ & $2,58 \mathrm{a}$ \\
\hline Nutrientes digestíveis totais $(\mathrm{kg})$ & $2,26 \mathrm{c}$ & $3,09 \mathrm{~b}$ & $3,65 \mathrm{ab}$ & $4,02 \mathrm{a}$ \\
\hline Nutrientes digestíveis totais (\%) & $46,42 \mathrm{~d}$ & $54,92 \mathrm{c}$ & $60,75 b$ & $65,30 \mathrm{a}$ \\
\hline
\end{tabular}

Valores de ingestão de matéria seca seguidos com letras diferentes na mesma linha diferem entre si $(\mathrm{P}<0,08)$; valores dos demais itens diferem em $\mathrm{P}<0,05$. NDT do feno foi calculado pela equação NDT = 91,023-0,572(FDN\%) (Cappelle, 2001); NDT do milho estimado em 85\% (NRC, 1989).

equipamento Schimadzu 10 A, no Laboratório de Cromatografia do Departamento de Nutrição e Produção Animal(VNP) da FMVZ/USP, utilizando-se $1 \mu \mathrm{L}$ de amostra, com repetições quando a diferença entre leituras foi superior a 5\%. Solução padrão foi injetada depois de cada injeção de amostra para evitar possíveis distorções das leituras ocasionadas por contaminação da coluna.

Amostras de $2 \mathrm{~mL}$ de líquido ruminal foram colhidas também nos tempos 0, 2, 4 e 8 horas após a alimentação, preservadas com $1 \mathrm{~mL}$ de ácido sulfúrico $1 \mathrm{~N}$ e em seguida armazenadas em frascos de vidro devidamente etiquetados em congelador a $-10^{\circ} \mathrm{C}$ até o momento da análise laboratorial. A quantificação do nitrogênio amoniacal $\left(\mathrm{N}-\mathrm{NH}_{3}\right)$ foi realizada por colorimetria, pelo método de reação hipoclorito-fenol, segundo método proposto por Weatherburn (1967). Resumidamente, as amostras foram descongeladas, adicionadas de $1 \mathrm{~mL}$ de tungstato de sódio $10 \%$ para a desproteinização e centrifugadas a $3.000 \mathrm{rpm}$ por 15 minutos. Após centrifugação, $25 \mu \mathrm{L}$ do sobrenadante acrescidos de $5 \mathrm{~mL}$ de reagente fenol e $5 \mathrm{~mL}$ de reagente hipoclorito foram mantidos em banho-maria a $37^{\circ} \mathrm{C}$ por 15 minutos. As leituras em absorbância foram realizadas em espectrofotômetro a $630 \mathrm{~nm}$ (Perkin- Elmer Lambda 10).

Curvas diárias de $\mathrm{pH}$ foram determinadas em amostras do conteúdo ruminal colhidas nos mesmos tempos de AGV e amônia utilizando-se medidor eletrônico de pH (Hanna HI 9321), calibrado em solução tampão de pH 4,0 e 7,0.

Os dados obtidos foram analisados estatisticamente por meio de programa computacional (Hill \& Lewicki, 2006). Para teste de comparação de médias, utilizou-se o LSD, adotando-se nível de significância de 5\% para diferença significativa entre os tratamentos.

\section{Resultados e Discussão}

Os valores médios de $\mathrm{pH}$ no líquido ruminal não diferiram significativamente $(\mathrm{P}>0,05)$ entre os tempos de amostragem, o que difere das observações de GigerReverdim et al. (1991), Zhao et al. (1993), Dehority (2005) e Rustomo et al. (2006) de que a redução do pH ruminal ocorre logo após a alimentação e até 4 a 8 horas, dependendo da natureza da dieta e da rapidez como é ingerida. Assim, neste trabalho o tempo não influenciou significativamente o $\mathrm{pH}$ ruminal, apesar da tendência à diminuição dos valores de $\mathrm{pH}$ no tempo de 4 horas. Os valores de $\mathrm{pH}$ ruminal tiveram pequena variação entre os tempos de coleta, com amplitude de 6,23 (na dieta com $37 \%$ de milho na dieta, antes da alimentação) a 6,87 (na dieta exclusiva de feno, no tempo 2 horas), mantendo valores elevados, apesar da inclusão do amido do milho. A análise estatística dos dados indicou diferença significativa $(\mathrm{P}<0,05)$ no $\mathrm{pH}$ médio ruminal entre 
a dieta com $49 \%$ de milho $(6,62)$, que apresentou o mesmo valor que aquela com $37 \%$ de milho e aquelas sem milho $(6,78)$ e com $22 \%$ de milho em grão moído $(6,77)$. Houve correlação negativa entre os níveis de milho na dieta e o $\mathrm{pH}$ ruminal, com regressão linear significativa $(\mathrm{P}<0,02$ e r $=0,29): \mathrm{pH}=6,8-0,00324 \mathrm{X}$, em que X representa os níveis de milho em grãos na dieta. $O$ valor da constante - 0,00324 é muito baixo e indica valores elevados de $\mathrm{pH}$ em níveis elevados de milho na dieta. Esses achados confirmam outros dados obtidos com bubalinos em diversos sistemas de alimentação semelhantes. Kamra et al. (2003) observaram valores médios de $\mathrm{pH}$ variando de 6,72 a 7,16 no rúmen de bubalinos alimentados com dietas com 20,30, 40 e 50\% de concentrado. Nogueira Filho et al. (1999), avaliando o pH ruminal de búfalos mantidos com dietas com volumosos e concentrados por período de 24 horas, verificou $\mathrm{pH}$ ruminal médio de 6,24. Franzolin et al. (2000) também observaram valores elevados de $\mathrm{pH}$ no rúmen (média 6,85 ) de bubalinos alimentados com feno de coast-cross e concentrado (1:1) contendo diferentes níveis de milho em grão e polpa cítrica. Entretanto, contrariam os dados obtidos com bovinos e ovinos em pesquisa na qual o aumento no fornecimento de amido ou carboidratos solúveis em substituição aos carboidratos complexos da parede celular ocasionou redução acentuada do $\mathrm{pH}$, atingindo níveis abaixo de 5,5 com dietas ricas em concentrado (Kaufmann, 1976; Van Soest, 1994; Franzolin \& Dehority, 1996a; Franzolin \& Dehority, 1996b; Dehority, 2005). Silva et al. (2006) observaram baixo valor médio de $\mathrm{pH}$ ruminal $(5,58)$ em bovinos mestiços EuropeuZebu alimentados com silagem de milho (63\%) e concentrado (37\%). Rustomo et al. (2006) observaram em bovinos recebendo dietas contendo $50 \%$ de concentrado valores de 6,98 a 5,29 para o $\mathrm{pH}$ no rúmen. Não foi possível identificar razões para esses resultados, portanto, são necessários novos estudos para esclarecimento das causas para as curvas elevadas de $\mathrm{pH}$ ruminal em bubalinos mantidos com dietas com níveis crescentes de concentrado. Também é preciso investigar qual o nível de concentrado na dieta de búfalos que promoveria redução acentuada na curva de $\mathrm{pH}$ no rúmen.

Não foram observados efeitos significativos $(\mathrm{P}>0,05)$ dos níveis de milho na dieta sobre a concentração de amônia no líquido ruminal (Figura 1). Houve diferenças $(\mathrm{P}<0,05)$ nos valores médios de amônia entre os tempos de amostragem. A concentração de amônia no líquido ruminal teve pico 2 horas após o arraçoamento e diminuiu a seguir, confirmando dados obtidos por Paliwal \& Sagar (1990), Zanetti et al. (1995) e Sousa et al. (2000) em bubalinos. Os valores médios nos tempos de coleta de $0,2,4$ e 8 horas após a alimentação matutina foram de 5,$9 ; 11,6 ; 8,0$ e
$5,3 \mathrm{mg} / 100 \mathrm{~mL}$, respectivamente, e provavelmente refletiram o baixo teor de proteína nas dietas, que variaram de 6,9 a 10,6\% MS (Tabela 1). Os valores absolutos de proteína nas dietas exclusivamente com feno de capim coast-cross na relação $\mathrm{PB}: \mathrm{CNF}$ de 1,01 foram ligeiramente superiores aos das demais dietas e mais constantes após o pico, o que indica baixo teor de energia prontamente disponível para os microrganismos do rúmen em relação à disponibilidade de nitrogênio, uma vez que as demais dietas apresentaram baixa relação PB:CNF, de 0,39 a 0,26. Zanetti et al. (1995) verificaram concentração média de amônia ruminal de $17,18 \mathrm{mg} / 100 \mathrm{~mL}$ de líquido ruminal em bubalinos. Souza et al. (2000) observaram concentração média de 21,46 mg/100 mL de amônia ruminal em búfalos e bovinos alimentados com dietas com níveis crescentes de milho, de 2 a 15,5\% MS e teor médio de $12,8 \%$ de PB, mas não observaram diferenças entre as dietas. De forma semelhante, Kamra et al. (2003) obtiveram concentrações médias de amônia de 11,71 a 24,17 mg/100 mL de líquido ruminal em bubalinos alimentados com dietas com níveis crescentes de concentrado, até $50 \%$, porém com teor de milho em grão de 6 a $15 \%$ MS.

Não houve diferenças $(\mathrm{P}>0,05)$ nas concentrações dos ácidos acético e propiônico $(\mathrm{mM})$, no entanto a concentração molar de ácido butírico aumentou $(\mathrm{P}<0,05)$ com a adição de milho na dieta. Entretanto, na avaliação da proporção molar entre os três principais ácidos graxos voláteis (Tabela 2), observou-se efeito significativo $(\mathrm{P}<0,05)$ do aumento da porcentagem de milho em grão moído na dieta na diminuição das concentrações de ácido acético e no aumento da porcentagem molar de ácido propiônico quando os animais receberam $49 \%$ de milho em grão moído, o que comprova

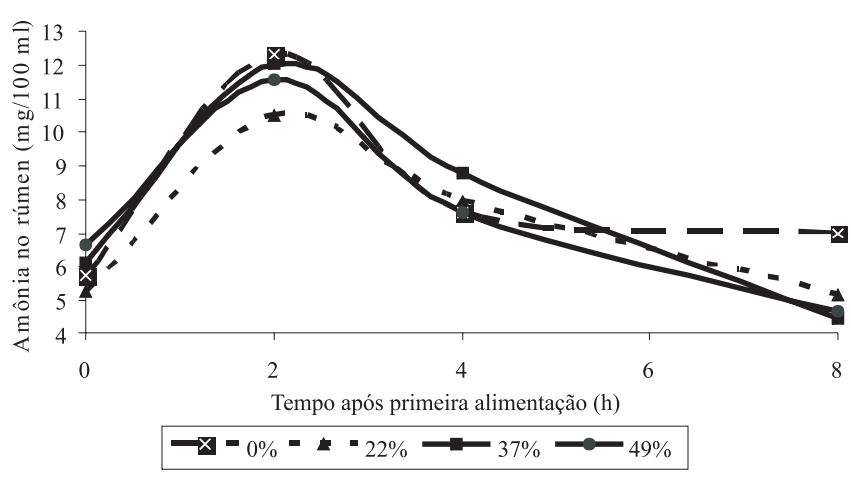

Figura 1 - Concentrações médias de amônia $(\mathrm{mg} / 100 \mathrm{~mL})$ no líquido ruminal em diversos tempos de amostragem em bubalinos mantidos com dietas contendo níveis crescentes de milho em grão moído $(0,22,37$ e 49\% MS) e feno de gramínea. 
Tabela 2 - Concentrações médias e proporções molares de ácidos acético, propiônico e butírico no líquido ruminal em bubalinos com dietas contendo níveis crescentes de milho em grão moído e feno de gramínea

\begin{tabular}{|c|c|c|c|c|c|}
\hline Ácido & \multicolumn{5}{|c|}{ Nível de milho em grão moído na dieta (\% MS) } \\
\hline Acético $(\mathrm{mM})$ & 53,35 & 57,17 & 51,82 & 52,13 & 53,62 \\
\hline Butírico $(\mathrm{mM})$ & $4,81 \mathrm{~b}$ & $7,84 \mathrm{a}$ & $7,99 \mathrm{a}$ & $7,99 \mathrm{a}$ & 7,15 \\
\hline Total (mM) & 68,32 & 76,47 & 70,9 & 71,88 & 71,89 \\
\hline Propiônico (mM) & $14,88 b$ & $14,85 b$ & $15,73 b$ & $16,73 \mathrm{a}$ & 15,55 \\
\hline Butírico $(\mathrm{mM})$ & $7,04 \mathrm{c}$ & $10,09 \mathrm{~b}$ & $11,26 \mathrm{a}$ & $10,73 \mathrm{ab}$ & 9,78 \\
\hline
\end{tabular}

Valores seguidos de letras diferentes na mesma linha diferem entre si $(\mathrm{P}<0,05)$.

melhora na disponibilidade energética das rações com o aumento dos níveis de milho em grão em substituição ao feno de coast-cross. A concentração total de ácidos graxos voláteis média obtida neste experimento, de $71,89 \mathrm{mM}$, foi próxima ao valor encontrado por Souza et al. (2000) com bubalinos mantidos com dietas com diferentes níveis de FDN (69,94 mM). Kamra et al. (2003) observaram que a proporção molar dos ácidos graxos voláteis no rúmen não foi afetada pelo aumento de concentrado na dieta de bubalinos com $6-15 \%$ de milho em grão. Esses autores obtiveram valores médios de 73,2; 21,5 e 5,3 mM para os ácidos acético, propiônico e butírico, respectivamente. Os animais recebendo níveis crescentes de milho em grão na dieta (22, 37 e 49\% MS) apresentaram concentração média de ácido butírico $(7,94 \mathrm{mM}) 60 \%$ superior à observada naqueles alimentados exclusivamente com feno $(4,81 \mathrm{mM})$, o que indica maior fermentação por bactérias que produzem ácido butírico quando há maior disponibilidade energética na dieta em relação ao nível de proteína, sugerindo ser uma característica da espécie bubalina. De fato, Valadares Filho et al. (1990) observaram que a concentração de ácido butírico em bubalinos é maior que em bovinos holandeses e não encontraram explicação para esse fato.

A relação acético:propiônico $(\% \mathrm{M})$ diminuiu com o aumento dos níveis de milho na ração, com valores de 5,2; 5,$1 ; 4,7$ e 4,3 para as dietas com 0, 22, 37 e 49\% de milho em grão, respectivamente (Figura 2). Esse resultado está de acordo com as afirmações de Kaufmann (1976) e Fahey \& Berger (1988) de que essa relação depende da proporção de volumoso:concentrado na dieta, uma vez que o teor de fibra na dieta aumenta a relação acético:propiônico. Entretanto, Sousa et al. (2000) não observaram diferenças significativas nas concentrações de acético, propiônico e butírico e na relação acético:propiônico em bubalinos alimentados com diferentes níveis de FDN.

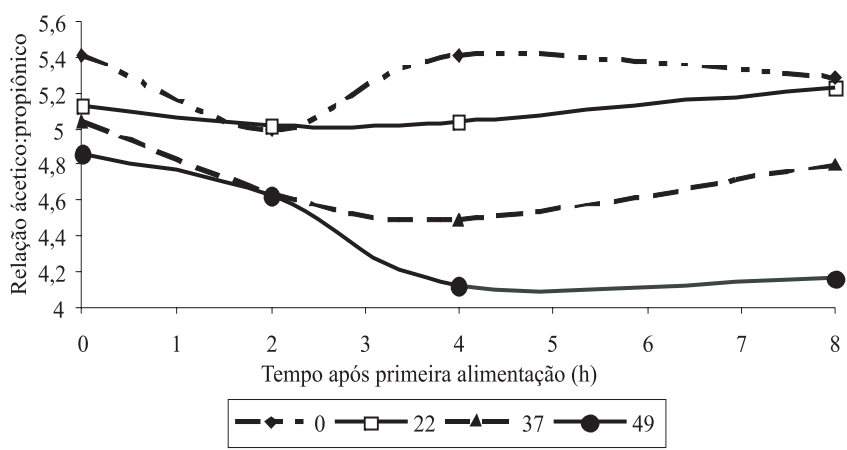

Figura 2 - Relação acético:propiônico no líquido ruminal em diversos tempos de coleta em bubalinos alimentados com dietas com níveis crescentes de milho em grãos moídos (0, 22, 37 e 49\% MS) e feno de gramínea.

\section{Conclusões}

A substituição do feno de coast-cross por milho em grão moído em níveis de 22, 37 e 49\% em dietas para bubalinos altera o padrão de fermentação ruminal, principalmente aumentando o teor de ácido butírico e reduzindo a relação acético:propiônico, todavia não influencia o $\mathrm{pH}$ no rúmen, que se mantém elevado (média de 6,70). A relação proteína bruta:carboidratos não-fibrosos em dieta composta exclusivamente de feno $(1,01)$ promove maior concentração de amônia no rúmen ao longo do dia, o que indica menor eficiência de síntese microbiana em comparação a dietas com relação proteína bruta:carboidratos não-fibrosos inferior a 0,39 .

\section{Agradecimentos}

À Faculdade de Zootecnia e Engenharia de Alimentos da Universidade de São Paulo, pelo desenvolvimento do curso de mestrado em Zootecnia, e à CAPES, pelo suporte financeiro com a bolsa de mestrado. 


\section{Literatura Citada}

CAMERON, M.R.; KLUSMEYER, T.H.; LYNCH, G.L. et al. Effects of urea and starch on rumen fermentation, nutrient passage to the duodenum, and performace of cows. Journal of Dairy Science, v.74, p.1321-1331, 1991.

CAPPELLE, E.R.; VALADARES FILHO, S.C.; SILVA, J.F.C. et al. Estimativas do valor energético a partir de características químicas e bromatológicas dos alimentos. Revista Brasileira de Zootecnia, v.30, n.6, p.1837-1856, 2001.

DEHORITY, B.A. Effect of $\mathrm{pH}$ on viability of Entodinium caudatum, Entodinium exiguum, Epidinium caudatum, and Ophryoscolex purkynjei in vitro. Journal of Eukaryotic Microbiology, v.52, n.4, p.339-342, 2005.

ERWIN, E.S.; MARCO, G.J.; EMERY, E.M. Volatile fatty acid analyses of blood and rumen fluid by gas chromatography. Journal of Dairy Science, v.44, p.1768-1771, 1961.

FAHEY JR., G.C.; BERGER, L.L. Carbohydrate nutrition of ruminants. In: CHURCH, D.C. The ruminant animal. Englewood Cliffs: Waveland Press, 1988. cap. 14, p.269-297.

FRANZOLIN, R.; DEHORITY, B.A. Effect of prolonged highconcentrate feeding on ruminal protozoa concentrations. Journal of Animal Science, v.74, n.11, p.2803-2809, 1996a.

FRANZOLIN, R.; DEHORITY, B.A. Effects of ruminal $\mathrm{pH}$ and feed intake on defaunation in sheep fed high concentrate diets. Revista Brasileira de Zootecnia, v.25, n.6, p.1207-1215, 1996b.

FRANZOLIN, R.; FRANZOLIN, M.H.T.; GOMIDE, C.A. et al. Efeitos de dietas com polpa cítrica em substituição ao milho em grãos no concentrado sobre a degradabilidade e a fauna ruminal em bubalinos. Revista Brasileira de Zootecnia, v.29, n.6, p.2109-2118, 2000.

GIGER-REVERDIN, S.; SAUVANT, D.; NAJAR, T. et al. Diet influence on biological degradation in sacco of cell walls by ruminants. Animal Feed Science and Technology, v.32, n.1, p.223-227, 1991.

HILL, T.; LEWICKI, P. Statistics: methods and applications. A comprehensive reference for science, industry and data mining. 1.ed. Tulsa: StaSoft, 2006. 832p.

KAMRA, D.N.; SAHA, S.; BHATT, N. et al. Effect of diet on enzyme profile, biochemical changes and in sacco degradability of feeds in the rumen of buffalo. Asian-Australasian Journal of Animal Sciences, v.16, n.3, p.374-379, 2003.

KAUFMANN, W. Influence of the composition of the ration and the feeding frequency on $\mathrm{pH}$-regulation in the rumen and feed intake in ruminants. Livestock Production Science, v.3, n.2, p. 103-114, 1976 .

NATIONAL RESEARCH COUNCIL - NRC. Nutrient requirements of dairy cattle. 6.rev.ed. Washington, D.C.: National Academia Press, 1989. 157p.
NOGUEIRA FILHO, J.C.M.; OLIVEIRA, M.E.M.; TOLEDO, L.R.A. et al. Volume líquido, taxa de turnover e ciliados no rúmen de zebuínos e bubalinos submetidos a dietas com volumosos e concentrados. In: REUNIÃO ANUAL DA SOCIEDADE BRASILEIRA DE ZOOTECNIA, 36., 1999, Porto Alegre. Anais... Porto Alegre: Sociedade Brasileira de Zootecnia, 1999. p.273. (CD-ROM).

PALIWAL, V.K.; SAGAR, V. Effect of dietary fiber protein on rumen microbial fermentation in cattle and buffalo. Indian Journal of Animal Science, v.60, n.1, p.66-70, 1990.

RUSSEL, J.B.; HESPELL, R.B. Microbial rumen fermentation. Journal of Dairy Science, v.64, n.6, p.1153-1169, 1981.

RUSTOMO, B.O.; ALZAHAL, J. P.; CANT, M. Z. et al. Acidogenic value of dairy feeds: II. Effects of rumen acid load from dairy feeds on ruminai $\mathrm{pH}$, fibre digestibility, dry matter intake, and milk production in the lactating dairy cow. Canadian Journal Animal Science, v.86, n.1, p.119-126, 2006.

SILVA, A.V.; PEREIRA, O.G.; VALADARES FILHO, S.C. et al. Consumo e digestibilidade dos nutrientes em bovinos recebendo dietas contendo silagens de milho e sorgo, com e sem inoculante microbiano. Revista Brasileira de Zootecnia, v. 35 , n.6, p.2469-2478, 2006.

SILVA, D.J.; QUEIROZ, A.C. Análise de alimentos: métodos químicos e biológicos. 3.ed. Viçosa, MG: Universidade Federal de Viçosa, 2002. 235p.

SOUZA, N.H; FRANZOLIN,R; RODRIGUES,P.H.M. et al. Efeitos de níveis crescentes de fibra em detergente neutro na dieta sobre a fermentação ruminal em bubalinos e bovinos. Revista Brasileira de Zootecnia, v.29, n.5, p.1553-1564, 2000.

VALADARES FILHO, S.C.; COELHO DA SILVA, J.F.; LEÃO, M.I. et al. Digestibilidade in vitro e alguns parâmetros de fermentação ruminal medidos em novilhos holandeses, nelores e búfalos mestiços alimentados com ração purificada. Revista Brasileira de Zootecnia, v.19, n.5, p.441-449, 1990.

VAN SOEST, P.J. Nutritional ecology of the ruminant. Corvallis: O \& B Books Inc., 1994, 374p.

WEATHERBURN, M.W. Phenol-hypochlorite reaction for determination of ammonia. Analytical Chemistry, v.39, n.8, p.971-974, 1967.

ZANETTI, M.A.; NOGUEIRA FILHO, J.C.; OLIVEIRA, M.E.M. et al. Níveis de amônia ruminal em bovinos da raça Nelore e em búfalos da raça Mediterrâneo. In: REUNIÃO ANUAL DA SOCIEDADE BRASILEIRA DE ZOOTECNIA, 32., 1995, Brasília. Anais... Brasília: Sociedade Brasileira de Zootecnia, 1995. p.351-352.

ZHAO, J.Y.; SHIMOJO, M.; GOTO, I. The effects of feeding level and roughage/concentrate ratio on the measurement of protein degradability of two tropical forages in the rumen of goats, using the nylon bag technique. Animal Feed Science and Technology, v.41, n.4, p.261-269, 1993. 